\title{
ROLE OF CERTAIN BEAUVERIA BASSIANA \\ ISOLATE AS BIOLOGICAL CONTROL AGENT \\ AGAINST WHITEFLY, BEMISIA TABACI (GENN.) \\ AND ITS EFFECT ON THE PREDATOR CHRYSOPELA CARNEA (STEPHENS)
}

\author{
Iman I. Imam \\ Economic Entomology Unit, Department of Plant Protection, Desert \\ Research Center, El-Matareya, Cairo, Egypt \\ E-mail: imann_7298@yahoo.com
}

$\mathrm{T}$

he lethal effect of Beauveria bassiana isolate on whitefly Bemisia tabaci revealed that the least percentage of adult mortality was $11 \%$, which was recorded with the lowest tested concentration $\left(1 \mathrm{X} 10^{3}\right.$ spores $\left./ \mathrm{ml}\right)$, while the highest percentage of adult mortality $(56 \%)$ was achieved at $1 \times 10^{7}$ spores $/ \mathrm{ml}$, compared with $5 \%$ in natural mortality. In a similar trial to evaluate the effect of $B$. bassiana against the aphid lion Chrysopela carnea (Stephens), exposure of the $2^{\text {nd }}$ larval instar of aphid lion to $B$. bassiana isolate, either through direct or indirect exposure, resulted in adverse effects on the total percent of larval mortality, which was concentration dependent. Whereas the total larval death recorded $3 \%$ in control trials, data in case of direct exposure revealed 9 to $41 \%$ of larval death at $1 \times 10^{3}$ and $1 \times 10^{7}$ spores/ml, respectively. Comparable trend was recorded with larvae indirectly exposed. Increase in larval mortality was recorded by 5 to $15 \%$. Therefore, care is needed when using these fungal isolates in the case of using larval predator aphid lion in the programs of integrated control.

Keywords: Beauveria bassiana, Bemisia tabaci, Chrysopela carnea, integrated control

Natural enemies (predators and parasites) play a very important part in controlling pest populations. Green lacewing; Chrysoperla carnea (Stephens), is known as an insect in the Chrysopidae family. The adults feed on nectar, pollen and aphid honeydew and are not predatory, but the larvae are efficient biocontrolling predators against many key pests including aphids, whiteflies, young larvae and eggs of Lepidoptera, mealy bugs, spider mites and soft bodied arthropods (El-Arnaouty and Ferran, 1993 and Hassan, 2003). It can be mass reared in the laboratory and released against pests in field and greenhouses (Mirnoayedi, 2001). 
The whitefly, Bemisia tabaci Genn. (Hemiptera: Aleyrodidae), is an economically important pest in many ornamentals and vegetables grown in greenhouses and fields all over the world (Helle and Sabelis, 1985; Lewis, 1997; CAB International, 2007 and Vincent et al., 2007). B. tabaci poses a serious threat to the greenhouse vegetable industry because of its resistance to many pesticides, and as an efficient vector for numerous plant viruses (Gerling, 1990).

Fungal microbial control agent offers a method of insect pest control that can be integrated with other biocontrol agents, B. bassiana was ubiquitous as an entomopathogen of a wide range of insects from most insect orders (Goettel and Jaronski, 1997). However, the success of fungal entomopathogens as biological control agents depends not only on high efficacy against insect pests, but also on low virulence against non-target insects.

The present study deals with direct effect of Beauveria bassiana isolate on Bemisia tabaci and Chrysopela carnea (Stephens) as well as the indirect effect on the predator fed on treated whitefly.

\section{MATERIALS AND METHODS}

\section{Tested Insects}

The predator, $C$. carnea was initially collected from the cotton field and reared on Angoumois grain moth, Sitotroga cerealella (Olivier) at the same mentioned laboratory conditions. The adults of $C$. carnea were sexed and 10 pairs of adults were placed in plastic boxes $(22 \times 13 \times 10 \mathrm{~cm})$ covered with black muslin for deposited eggs and changed daily. Drops of semi artificial diet solution consists of $2 \mathrm{~g}$ yeast extract, $1 \mathrm{~g}$ fructose and $1 \mathrm{~cm}$ distilled water were provided on tape stacked on the muslin cover. The deposited eggs were collected daily and kept in glass jars until hatching. The hatched larvae were reared on S. cerealella eggs (Hassan and Ezz 2009).

Bemisia tabaci Genn. was colleted from infested plants in a commercial plantation in Salhiya City; they were reared on the underside of detached common bean leaves, $P$. vulgaris, which were put on top of a moist sponge placed inside a box $(35 \times 115 \times 115 \mathrm{~mm})$.

\section{Fungus Culture}

The fungal isolate Beauveria bassiana was isolate from soil samples, using the soil plate method (Warcup, 1950). Both light and electron microscopy were used for examination and identification of the fungal isolate according to Raper and Fennel (1965) and Samson et al. (1995). The B. bassiana isolate was cultured on liquid medium after purification by sub-culturing on potato dextrose agar (PDA) medium. One disc contain spores was cut from edge of actively growing culture and inoculated under aseptic condition in each sterilized media (adjusted at $\mathrm{pH}$ 6.5) of potato dextrose broth (PDB $50 \mathrm{ml})$ medium in Erlenmeyer flask $(250 \mathrm{ml}$ capacity). The fungal 
isolate was transferred to an incubator maintaining $28 \pm 2^{\circ} \mathrm{C}$. After 14 days of incubation period, the mycelial mat of isolate was harvested, washed with distilled water for several times, extracted by refluxing in boiled methanol for 2 hours and then filtered off. The mycelial residue was reextracted again for three times. The combined filtrates were concentrated under reduced pressure at temperature not exceeding $35^{\circ} \mathrm{C}$. The obtained residue was kept in refrigerator for investigation against the target insect. The filter of isolate was extracted by $n$-butanol. This step was repeated until complete extraction. The butanolic extract was filtered on anhydrous of sodium sulphate. Fungal suspension concentrations were adjusted by estimation on a haemocytometer (hirscmann $0.1 \mathrm{X} 0.0025 \mathrm{~mm}^{2}$ ).

\section{Toxicity Test}

\subsection{Method of application on B. tabaci}

To determinate the effect of the Beauveria bassiana isolate on whitefly, assay was carried out on adult (2-3 days old). Three concentrations $\left(1 \times 10^{3}, 1 \times 10^{5}\right.$ and $1 \times 10^{7}$ spores $\left./ \mathrm{ml}\right)$ of fungal suspension were used. Treatments and control were represented with three replicates and each replicate consisted of ten adults of B. tabaci. Each replicate was sprayed with $1 \mathrm{ml}$ of fungal suspension in small plastic cages then transferred to $9 \mathrm{~cm}$ Petri dish. Control was treated with water. Daily mortality rates were noted and dead adults were monitored for mycosis symptoms. Data were analyzed for determination of the lethal concentration $\left(\mathrm{LC}_{50}\right)$.

\subsection{Method of application on $C$. carnea larvae}

\subsubsection{Direct effect}

The residual film technique was used. Three $\mathrm{ml}$ of the desired concentration were evenly spread on a Petri dish surface $(9 \mathrm{~cm}$ in diameter). The solvent allowed being evaporated leaving a film of several concentration of fungal isolate $\left(1 \times 10^{3}, 1 \times 10^{5}\right.$ and $1 \times 10^{7}$ spores $\left./ \mathrm{ml}\right)$ the $2^{\text {nd }}$ larval instar of aphid lion were exposed to the thin film for 24 hour and offer them the appropriate amount of whitefly as food. The concentration was replicated six times; five Petri dishes for each containing three larvae. The control specimens were treated with water.

\subsubsection{Indirect effect}

The second larval instar of aphid lion were fed on appropriate amount of whitefly previously sprayed with the previous concentrations of fungal isolate, then immediately placed with $2^{\text {nd }}$ instar larvae of aphid lion. The control specimens were treated with water. Daily inspections were conducted.

\section{Statistical Analysis and Assessment of Results}

Data obtained from different tests were tested for normality then subjected to statistical analysis to evaluate the relative efficiency of the 
isolate. Mortalities were corrected for the natural mortality according to (Abbott's formula, 1925).

The corrected percent $=($ Observed \% - Control \%) x 100/(100-Control \% $)$.

Concentration/mortality regression lines were drawn on probit logarithmic graph according to the method developed by Finney (1971). The $\mathrm{LC}_{50}$ and $\mathrm{LC}_{90}$ values were calculated according to probane program percent of hatchability of the resulted females and were calculated according to Zidan et al. (1998) as follows:

$\%$ Hatchability $=[$ No. of hatched eggs $/$ No. of deposited eggs $] \times 100$

\section{RESULTS AND DISCUSSION}

\section{Toxic Effect of $B$. bassiana Isolate}

\subsection{Effect on $B$. tabaci}

The effect of $B$. bassiana isolate on $B$. tabaci were recorded and tabulated. Data obtained presented in Table (1), showed that the least percentage of adult mortality was $11 \%$, which was recorded with the lowest tested concentration $\left(1 \times 10^{3}\right.$ spores $\left./ \mathrm{ml}\right)$, while the highest percentage of adult mortality was $56 \%$ and was achieved at $1 \times 10^{7}$ spores $/ \mathrm{ml}$, compared with $5 \%$ in natural mortality. Data were detected on the basis of the calculated $\mathrm{LC}_{50}$ and $\mathrm{LC}_{90}$ values, which recorded $78958 \times 10^{6}$ and $86241 \times 10^{10}$ spores $/ \mathrm{ml}$, respectively (Fig. 1).

According to the recorded data, all applied concentrations of $B$. bassiana isolate reduced the population of white fly adults. Griffin (1994) stated the following fact; fungi secret wide array of compound is biologically active against other organisms. Goettel and Jaronski (1997) decided that $B$. bassiana was ubiquitous as an entomopathogen of a wide range of insects from most insect orders. It is recorded and used in suppressing population of several economically important insects including whiteflies, aphids, mealybugs, lepidopteran eggs and mites (Vandenberg et al., 1998 and Ezz, 2004). These record that death percentages may be attributed to paralysis (mouthpart or midgut) and/or cytotoxin effect (Maketon et al., 2008).

Table (1). Toxic effect of B. bassiana isolate on 2-3 days old adult of B. tabaci.

\begin{tabular}{ccc}
\hline $\begin{array}{c}\text { Concentration } \\
\text { (spores/ml) }\end{array}$ & \multicolumn{2}{c}{ Mortality \% after 3days } \\
\cline { 2 - 3 } & Observation & Correction \\
\hline 0 & 5 & 0.00 \\
$1 \mathrm{X} 10^{3}$ & 11 & 6.32 \\
$1 \mathrm{X} 10^{5}$ & 23 & 18.95 \\
$1 \mathrm{X} 10^{7}$ & 56 & 53.68 \\
\hline
\end{tabular}

Egyptian J. Desert Res., 67, No. 2, 351-359 (2017) 


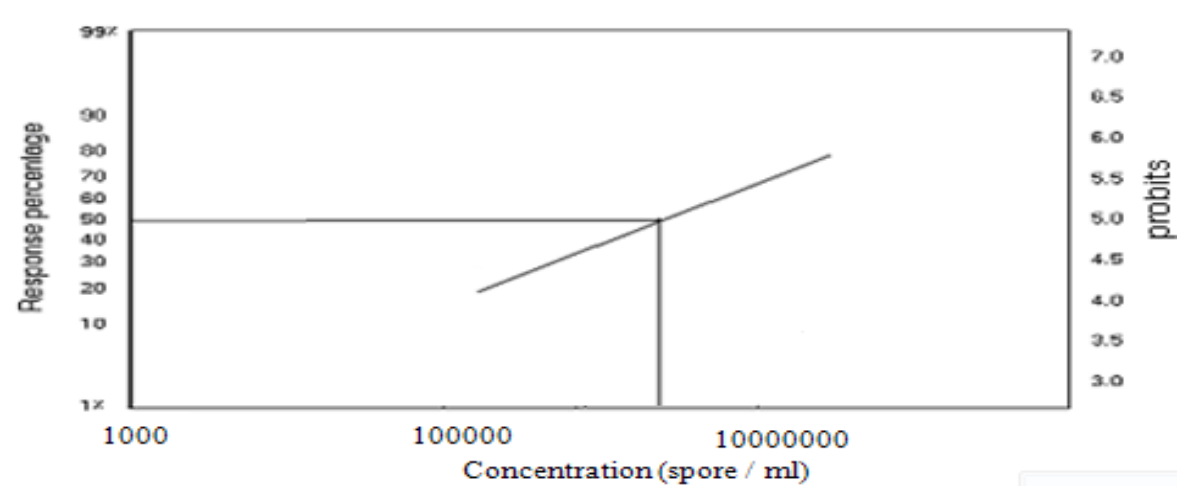

Fig. (1). Concentration / mortality regression lines for $B$. tabaci adults treated with B. bassiana isolate

\subsection{Effect on $C$. carnea larvae}

Exposure of the $2^{\text {nd }}$ larval instar of aphid lion to $B$. bassiana isolate either through direct or indirect exposure procedure revealed adverse effects on the total percent of larval mortality, which was concentration dependent. Whereas the total larval death recorded 3\% in control trials, data in case of direct exposure revealed 9 to $41 \%$ of larval death at $1 \times 10^{3}$ and $1 \times 10^{7}$ spores $/ \mathrm{ml}$, respectively. Comparable trend was recorded with larvae indirectly exposed. A slight increase in larval mortality was recorded by 5 to $15 \%$, respectively (Table 2). Such mentioned data show that, although the tested $B$. bassiana isolate had the same mode of action in both exposure techniques, the drastic larval death in the direct exposure method may be attributed to that the concentration of $B$. bassiana isolate, exceeded that in case of indirect method.

The direct effect of $2^{\text {nd }}$ larval instar of aphid lion to B. bassiana isolate, could be detected on the basis of the $\mathrm{LC}_{50}$ and $\mathrm{LC}_{90}$ values, which recorded $96279 \times 10^{7}$ and $6935 \times 10^{11}$ spores $/ \mathrm{ml}$, respectively, while the calculated $\mathrm{LC}_{50}$ and $\mathrm{LC}_{90}$ values of indirectly exposure technique recorded $10916 \times 10^{12}$ and $92341 \times 10^{18}$ spores/ml, respectively (Fig. 2). The result revealed that direct exposure technique was more effective than indirect exposure technique.

Bioassay program has been developing that allows direct exposing $C$. carnea $2^{\text {nd }}$ larval instar to the tested entomopathogenic fungus $B$. bassiana under laboratory conditions. $\mathrm{LC}_{50}$ of $B$. bassiana treated isolate is more than the highest concentration tested. That agrees to demonstration of Thungrabeab and Tongma (2007), who assumed that $B$. bassiana was to be nonpathogenic to Chrysopela externa (Hagen) with the highest fungal concentration. In disagreement with that, Sewify and El-Arnaouty (1998) found harmful effects of two isolates of Verticillium lecanii on Chrysopela carnea larvae with significant 
difference between pathogenicity of the isolates. Nevertheless; different genera, species or strains of entomopathogenic fungi had different pathogenicity and virulence (Goettel, 1995).

Table (2). Toxic effect of B. bassiana isolate on $2^{\text {nd }}$ instar larvae of C. carnea.

\begin{tabular}{ccccc}
\hline \multirow{2}{*}{$\begin{array}{c}\text { Concentration } \\
\text { (spores/ml) }\end{array}$} & \multicolumn{4}{c}{ Mortality \% after 3 days } \\
\cline { 2 - 5 } & \multicolumn{2}{c}{ Direct effect } & \multicolumn{2}{c}{ Indirect effect } \\
\cline { 2 - 5 } & Observation & Correction & Observation & Correction \\
\hline 0 & 3 & 0.00 & 3 & 0.00 \\
$1 \times 10^{3}$ & 9 & 6.19 & 5 & 2.06 \\
$1 \mathrm{X} 10^{5}$ & 19 & 16.49 & 9 & 6.18 \\
$1 \mathrm{X} 10^{7}$ & 41 & 39.17 & 15 & 12.37 \\
\hline
\end{tabular}
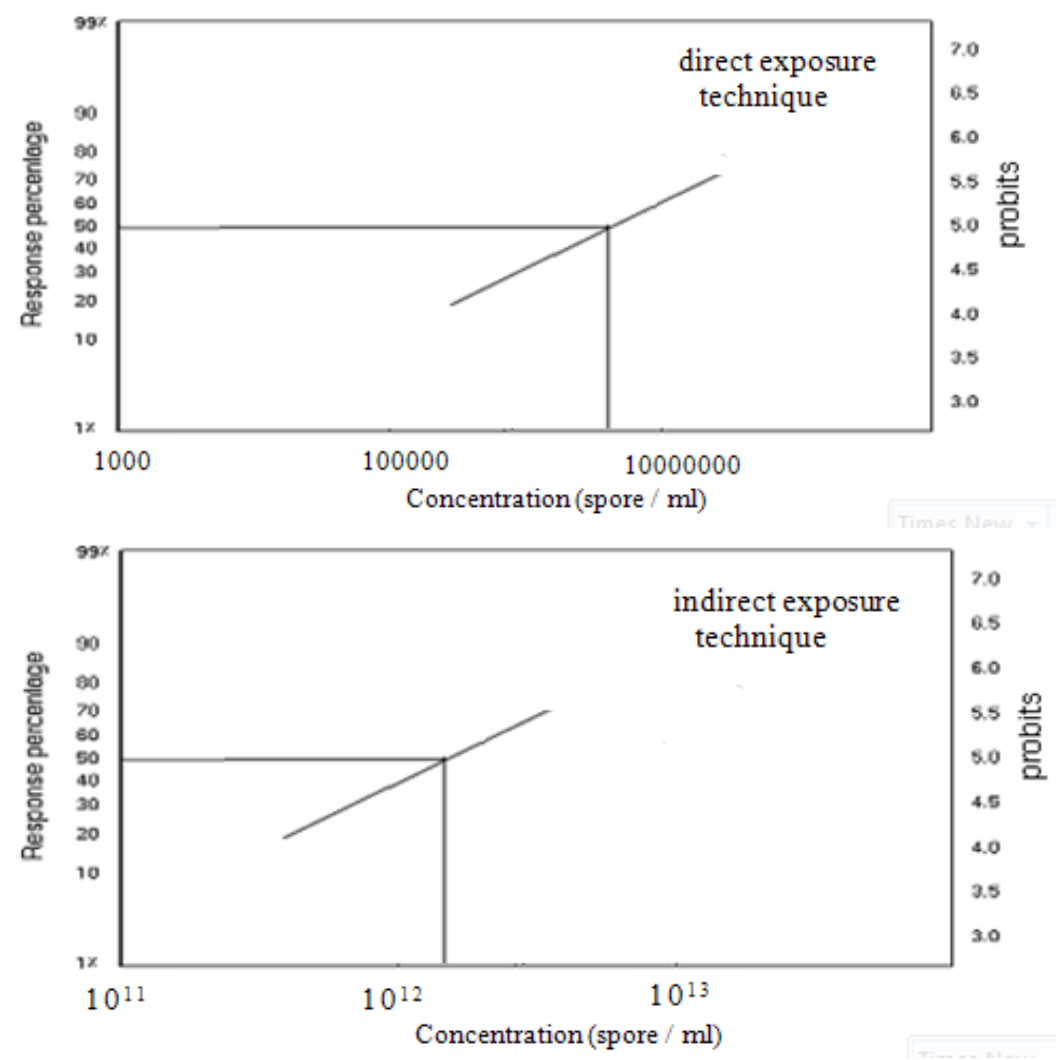

Fig. (2). Concentration / mortality regression lines for aphid lion larvae treated with $B$. bassiana isolate.

Egyptian J. Desert Res., 67, No. 2, 351-359 (2017) 


\section{REFERENCES}

Abbott, W.S. (1925). A method of computing the effectiveness of an insecticide. J. Econ. Entomol., 18: 265.

CAB International (2007). Animal Health and Production Compendium. CAB International.

El-Arnaouty, S.A. and A. Ferran (1993). Behavioral relations between the green lacewings, Chrysoperla carnea Steph. and its preys. Egypt J. Biol. Pest Control, 3(1): 111-120.

Ezz, N.A. (2004). Isolation and virulence of entomopathogenic fungi associated of microbial pesticides on non-target beneficial arthropods. Agric. Ecosyst. Environ., 16: 203-254.

Finney, C.E. (1971). In "Probit Analysis, A statistical Treatment of the sigmoid Response Curve". $7^{\text {th }}$ Ed. Cambridge Univ. Press, Cambridge, England FEMS Microbial. Lett., 231: 45-52.

Gerling, D. (1990). In "Natural Enemies of Whiteflies: Predators and Parasitoids". Whiteflies: Their Bionomics, Pest Status and Management. (D. Gerling, Ed.). Intercept, Andover, UK, p. 147-185.

Goettel, M.S. (1995). The utility bioassays in the risk assessment of entomopathogenic fungi. (biotechnology risk assessment USEPA/USDA, Environmental Canada, Agriculture and AgrioFood, Canda Proceeding of the Biotechnology, Risk Assessment Symposium, June, 6-8.

Goettel, M.S. and S.T. Jaronski (1997). Safety and registration of microbial agents for control of grasshoppers and locusts. Memoirs of the Entomological Society of Canada, 171: 83-99.

Griffin, D.H. (1994). In "Fungal Physiology". Wiley-liss, New York, 458 pp.

Hassan, K.A. (2003). Trials for mass-rearing and release for some predacious insect for controlling of pink and spiny bollworms. Ph.D. Thesis, Zagazig Univ., $180 \mathrm{pp}$.

Hassan, K.A. and Nahla A. Ezz (2009). Inpact of the entomopathogenic fungus Beauveria bassiana (Bals.) vuill on the predator Chrysopela carnea (Stephens) (Neuroptera: Chrysopidae). Bull. Ent. Soc. Egypt, Econ. Ser., 35: 9-17.

Helle, W. and M.W. Sabelis (1985). In “Spider Mites”. Their biology, Natural Enemies and Control. Elsevier.

Lewis, T. (1997). In "Thrips as Crop Pests". London: CAB International.

Maketon, M., P. Orosz-Coghlan and D. Hotaga (2008). Field evaluation metschnikoff (Metarhizium anisopliae) Sorokin in controlling cotton jassid (Amrasca biguttula biguttula) in Aubergine (Solanum aculeatissimum). Int. Agr. Biol., 10(1): 4751.

Mirnoayedi, A. (2001). The effect of experimental release of eggs and larvae of Ch. Carnea insect, Neuroptera, Chrysopidae on the reduction of the 
attack of Earias insulana, on cotton bolls, in Kermanshah, Iran. The first Conference on Integrated Pest Management, 22-23 April, Cairo, Egypt.

Raper, K.B. and D.I. Fennel (1965). In "The Genus Aspergillus". Baltimore, MD. Williams and Wilkins Company, Maryland, 686 p.

Samson, R., E. Hoekstra, J. Frisvad and O. Filtunborg (1995). Introduction of food borne fungi. Baarn and Lyngby, pp. 283297.

Sewify, G.H. and S.A. El-Arnaouty (1998). The effect of entomopathogenic fungus Verticillium lecanii (Zimm.) Vegas on nature larvae of Chrysopela carnea (Stephens) (Neuroptera: Chrysopidae) in the laboratory. Acta Zool. Fermica., 209: 233- 237.

Thungrabeab, M. and S. Tongma (2007). Effect of entomopathogenic fungi, Beauveria bassiana (Balsam) and Metarhizium anisopliae (Metsch.) on non-target insect. Kmitl Sci. Tech. J., 7(S1): 8-12.

Vandenberg, J.D., A.M. Shelton, W.T. Wilsey and M. Rams (1998). Assessment of Beauveria bassiana sprays for control of diamondback moth (Lepidoptera: Plutellidae) on crucifers. Biological and Microbial Control, 22: 624-630.

Vincent, C., M.S. Goettel and G. Lazarovits (2007). In "Biological Control: A global Perspective". CABI Wallingford, $440 \mathrm{p}$.

Warcup, J.H. (1950). The soil plate method for isolation of fungi from soil. Nature, 166: 117-118.

Zidan, Z.H., M.I. Abdel-Megeed, A. Abdel-Hafez, N.M. Hussein, H.M. ElGemeiy and M.M. Shalaby (1998). Toxicological and histological studies of Bacillus thuringiensis, MVPII against larvae of pink and spiny bollworms. Ann. Agri. Sci., 1: 319-332. 


\section{إستخذام بعض العزلات الفطرية. Beauveria bassiana Bais. كمستحضر مكافحة} بيولوجية على الذبابة البيضاء. Bemisia tabaci Genn. وكذلك أثره على المفترس أسد Chrysopela carnea Steph. المن

$$
\text { قسم وقاية النبات، مركز إيمام بحوث الصحر اء، المطرية، القاهرة، مصر }
$$

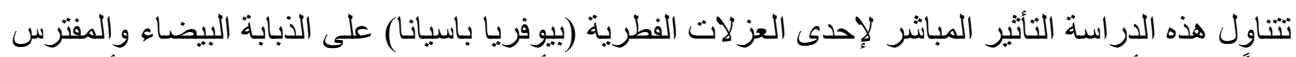

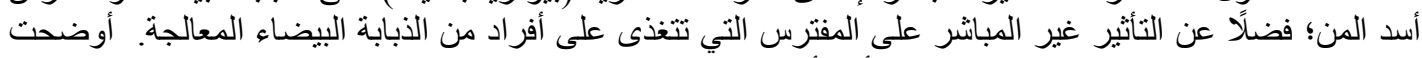

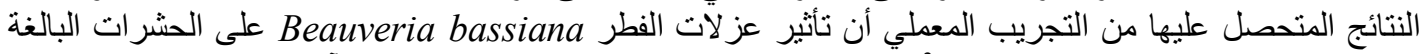

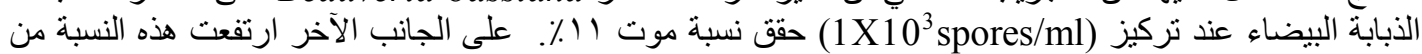

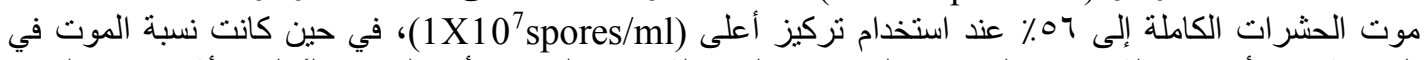

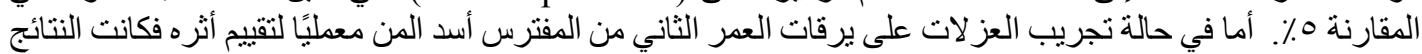

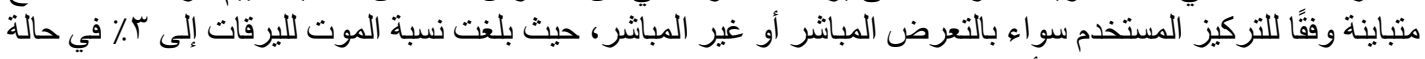

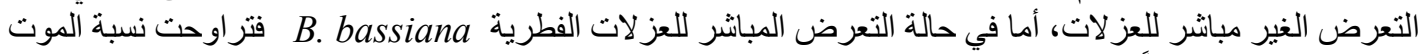

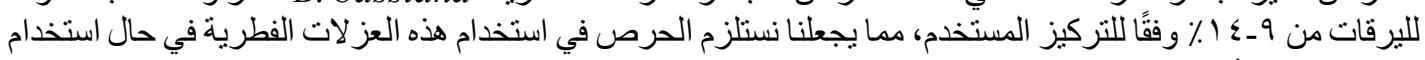
يرقات مفترس أسد المن في برامج المكافحة. 